Incentives and Adaptive Expectations in a Financial Market with Heterogenous Agents

\author{
Juanxi Wang
}




\title{
Incentives and Adaptive Expectations in a Financial Market with Heterogenous Agents
}

\author{
Juanxi Wang*
}

November 27, 2015

\begin{abstract}
This paper establishes an agent-based model to describe the dynamic behaviour of the financial market with mutual fund managers and investors under two types of compensation contracts: asset-based fees and performance-based fees, and using two types of adaptive expectation: trend chaser and contrarian. Our results show that both of trading strategies of trend chaser and contrarian destabilise the market. However, trend chasers always trigger significant fluctuations, while contrarian traders bring along the slight up and down oscillations. The types of compensation contracts change the behaviour of contrarian traders, but have no influence to trend chaser. We also find that inertia parameter decrease the stability of market and induce market price to be underestimated. In particular, the heterogenous analysis under different compensation contracts shows that asset maximisers dominate the whole market and produce higher returns, which can be used to explain the current situation in real market that most of mutual funds choose asset-based contract. Moreover, the coexistence of two compensation schemes may amplify market fluctuations and create bubbles.
\end{abstract}

Keywords: mutual fund manager, compensation contract, bounded rationality, adaptive expectation, nonlinear dynamics, risk taking behaviour, heterogenity JEL classification: E32, G11, H31

*J.Wang@uva.nl, Department of Business Administration and Economics, Bielefeld University; CeNDEF, Amsterdam School of Economics, University of Amsterdam 


\section{Introduction}

Since the creation of the first fund in 1924, mutual funds have mushroomed over the past ninety years. Rather than managed by private investors, a significant share of financial wealth is delegated to professional mutual fund managers. In 1940, there were approximately 68 funds with $\$ 0.45$ billions in assets. By the end of 2013, the number of funds have increased to 7707 . They are with $\$ 15,017.68$ billions in assets ${ }^{1}$. Nowadays, mutual funds and fund managers are playing important roles on financial industry. They control a large and increasing percentage of the aggregate wealth of investors. However, a potential conflict of interest between mutual fund managers and their investors arises from these considerable controls. Because a mutual fund can be considered as a black box which converts investor's cash into returns, what really happens inside the box remains unclear to investors (Malkiel, 1995).

The absence of costless, complete information and the presence of moral hazard are where these conflicts stem from. Baumol et al. (1989) suggested that the primary service supplied by mutual fund manager is portfolio management, which includes conducting research and making fund investment decisions. In return, fund managers receive compensation fees under advisory contract for providing those services. On the one hand, investor assumes that fund manager has common objective with him, which is to maximise expected fund's return. On the other hand, the resources fund manager expends on managing portfolio are in a black box and can not be observable directly. Investor cannot distinguish the effect of a manager's choice from the effect of the randomly determined state of nature. Likewise, exclusively from the observed outcome, investor cannot costlessly distinguish risk level of a manager's choice. Moreover, there are not many financial regulations to constrain the structure of compensation fees. As Jensen and Meckling (1976) suggested, many of the advisory contracts were only depended on the underlying contracting environment. The question arises is that whether the portfolio selected is optimal for investor as well as fund manager, since manager may choose a portfolio with risk level that is not compatible with investor's expectation.

Murphy (1999) suggested that it is optimal for contracts to provide a stronger link between compensation fees and investor welfare, particularly when investors know little about the production function linking managerial action and investors' objective func-

\footnotetext{
${ }^{1} 2014$ Investment Company Fact Book (http://www. icifactbook .org/index.html)
} 
tion. The task is to give fund manager a right incentive to make the best efforts and to achieve the same expectation as investor. This contract should detail a risk sharing rule with scheduled monetary rewards. It should also contain a compensation policy of managers. Stracca (2006) reviewed literature on delegated portfolio management with respects to a principal agent relationship between an investor (the principal) and a fund manager (the agent). He pointed out the fact that it was difficult to design an optimal contract which is compatible with the both incentives of investor and manager. The reason is that the manager controls all the efforts and the risks. In industry practice, people tend to favour simple compensation schemes. These schemes are usually asset-based and linearly depend on the value of the managed assets. As Ou-Yang (2003) suggested, a portfolio manager should receive a fixed with a fraction of the total assets under management. Holmstrom and Milgrom (1987) supported these asset-based compensations by showing that the linear sharing rule is an optimal contract as it induces an optimal trade-off between risk sharing and effort inducement.

In recent years, performance-based schemes have involved in the advisory contracts of many large mutual fund companies, which induced increasing policy discussions and research literature on performance-based incentives. Not like asset-based scheme which depends on the amount of assets, performance-based incentive scheme is based on the performance measures, such as net realised and unrealised gains. One of the claimed advantages of this incentive fee is that better fund's performance is expected from this sort of contract. From agency literature point of view, Starks (1987) showed that the symmetric type of performance-based compensation contract was in aligning the manager's interests with those of investors. Eichberger et al. (1999) also found the equilibriums where all fund mangers behave exactly as desired by investors. They suggested that the past relative performance-based reward schemes may arise as optimal contracts.

Moreover, some of the papers has found a significant effect of past performance on the mutual funds and the risk taking behaviour of their fund managers, which support the performance-based incentive contract further. Chevalier and Ellison (1997) provided empirical evidences that the fund's past returns create incentives for fund managers to alter their risk taking behaviours and to change their portfolio choices. There are more papers focused on the strong relationship between flows of new investment into mutual fund and their past performance, such as Ippolito (1992), Sirri and Tufano (1992), Patel 
et al. (1994), Roston (1996) and Goetzmann et al. (1997).

However, there are some arguments regarding whether or not performance-based scheme should be involved in advisory contract. Bines and Thel (2004) declaimed that fund manager under performance-based contract might fail to take into account many other components of management, such as portfolio diversification, risk management. Damato (2005) argued that performance-based fees might encourage fund managers to take excessive risks and gamble with their portfolios to obtain higher returns.Moreover, Mendoza and Sedano (2009) suggested that performance-based fees would fail to provide additional incentives to fund managers paid on increased assets.

Taken into account the rise of performance-based schemes and the popularity of asset-based schemes, comparing these two compensation schemes appears to be an important task. In this paper, in order to understand the implications of incentive contracts, we study a financial market with mutual fund managers and their clients under two compensation schemes: asset-based fees and performance-based fees. An agentbased model is established to describe the dynamic behaviours of a market with investors and mutual fund managers. Investors hire their fund managers according to managers' performance in the past. The manager with better past performance will attract more followers. For managers, they are myopic and make investment decisions by forecasting the market price in the following period. Therefore, the coexistence of two compensation schemes creates a heterogenous market with two types of fund managers: asset maximisers and return maximisers. Asset Maximisers are motivated by asset-based compensation schemes and aim to maximise the expected assets they manage. The managers who are under performance-based compensation schemes aim to maximise the returns of portfolios. This makes them to be Return Maximisers.

Our paper is very related with the study of Palomino (2005). They evaluated the consequence of an economy with the combination of fund managers' asset-based compensation schemes and investors' fund picking rules. Investors always use a relative performance rule to evaluate mutual fund managers and allocate money into funds. They found that these relative performance objectives increase the riskiness of the investment strategies. They also suggested that under the relative performance picking rules, asset-based compensation schemes increased investors' expected returns. In our paper, we also establish a model with the combination of fund managers' compensation schemes and investors' fund picking rules. However, instead of exclusively studying 
one contract, we investigate both asset-based and performance-based schemes. These two compensation schemes are also discussed in Cuoco and Kaniel (2011). They used a dynamic general-equilibrium setting while our paper considered agent-based model with multi-equilibriums. They found that asset-based fees distorted the risk level of managed portfolios. It increases asset prices and has negative effect on the performance of the investment. They also found that the effects of performance-based fees fluctuate stochastically over time in response to variations in the excess performance of funds. In our study, we give consistent results with all these papers, but under a complex system context. Moreover, we are able to observe the coexistence of these two contracts and the dynamic behaviour of the market.

One of the main contributions in this paper is that we not only observe a single type of fund manager in a homogenous market, but also show the complex behaviours that how heterogenous types of managers survive in a market. Most of the existing theoretical papers do not address explicitly the issue of multiple funds or heterogenous funds but only focus on a single fund with one manager, such as Grinold and Rudd (1987), Cohen and Starks (1988). They either investigated single manager and single investor or single manager and multiple investors.

Moreover, this paper is the first attempt to discuss fund manager by considering agent-based model. The highlight is that we considered the adaptive expectations and discussed the link between incentive contract and adaptive expectation of agents. A key assumption is that agents do not know the actual "law of motion" of the economy. Instead, they forecast the future upon time series observations (Simon, 1982). Sargent (1993), Evans and Honkapohja (2001) reviewed lots of related works on the adaptive learning in macroeconomics. In those papers, agents are bounded rational and use last observed price as an anchor and extrapolate the future price. In a series papers of Brock and Hommes (1997, 1998, 1999), they proposed Adaptive Belief Systems (ABS) which illustrated nonlinear dynamic asset-pricing models with evolutionary strategy switching. In those models, asset price is driven by an evolutionary dynamics of different adaptive expectations over time. Asset price fluctuations are characterised by irregular switching between a stable phase when fundamentalists dominate the market and an unstable phase when trend chasers dominate and asset prices deviate from rational expectation fundamentals. Boswijk et al. (2007) estimated a simple version of heterogeneous agent models on yearly S\&P 500 data and provide empirical evidence that stock prices can 
be characterised by the coexistence of two types of adaptive expectation - fundamentals and trend chasers. Moreover, these ABS models have been used to evaluate how likely it is that a stock market bubble will resume. Boswijk et al. (2007) suggested that price deviations from benchmark fundamentals are triggered by news about economic fundamentals but may be amplified by the strategy of trend chasers.

In our paper, two types of adaptive beliefs are observed - Trend Chaser and Contrarian. The manager who behaves as a trend chaser expects prices change to continue in the same direction. He buys assets when prices increase and sells them when prices decrease. On the contrary, a contrarian trader expects a reversal of the latest price change. He acts in an opposite way with trend chaser. He sells assets out when prices increase and buys them in when prices decrease. Brock and Hommes (1998) also investigated these two types of trading strategies. They found that both of trend chaser and contrarian trader destabilise the market. Contrarians cause a lot of up and down fluctuations around the fundamental, while trend chasers always trigger irregular switching between above and below the rational expectation fundamental. Those results also observed in this paper.

Intuitively, the types of compensation contract should have the same affects to trend chaser and contrarian. However, the results show that due to the significant fluctuations, the influence from compensation contract can barely be seen in the case of trend chasers. Moreover, the coexistence of two types of contracts and two types of adaptive expectations fails to stabilise the market. They turn the small oscillations into chaotic fluctuations. Both of contrarian trader and trend chaser favour asset-based contract, but there is always small fraction of them choose performance-based contract. Neither of the compensation contracts are able to drive the other type out of the market.

This paper is also the first attempt to investigate the nonlinear dynamic behaviour in both homogenous and heterogenous market regarding the relationships between investors and fund managers theoreticaly. Most of literature only considered one or two periods.

In a nutshell, the main research questions addressed in the paper are: Will the type of compensation scheme give change to the manager's risk taking behaviour? If so, what are their impacts to asset price and funds' performance in the long run? Is there any link between incentive contract and adaptive expectation? Will this link influence the instability of financial market? Is there any type of incentive scheme particularly 
favours certain type of adaptive expectation? Furthermore, what is the policy implications regarding compensation contract?

The model and analysis in this paper provided answers to these questions at two different aspects. Firstly, this paper reveals that the influence of compensation contract to fund managers under different adaptive expectations are different. Trend chasers do not care about the motivation contract. Their only concern is to chase the change of price. No matter under which kind of contracts, we do not observe the differences between two contracts. However, when it comes to the contrarian traders, the type of compensation schemes plays an important role when they make decisions to choose a portfolio. The different compensation schemes do change their risk taking behaviours. They are willing to take more risk if under asset-based contract. Second, this paper shows that when asset maximiser and return maximiser coexistent, asset maximisers dominate the whole market and produce higher returns. Furthermore, this paper investigates the inertia parameter which describes the possibility of an agent sticks to his previous strategy. The results show that it aways amplifies the fluctuations in different types of financial markets.

This paper is organised as following. Section 2 presents the model. Section 3 does the maximisation analysis. The simulation results of both homogenous and heterogenous market are shown in the Section 4 . The final section 5 closes this paper with a summary and conclusion.

\section{The Model}

\subsection{Basic Setup}

To begin with, assume that there are two kinds of assets in the market, a risk free asset and a risky asset. Agents can choose to invest in between them. Following standard theoretical literature, the risk free asset is referred to insured deposits or government securities. Risky asset stands for the market portfolio or the unit beta portfolio (Friedman and Abraham, 2009).

In this model, we assume that the risk free asset has a return rate of $r>0$ per unit per period. The price of the risk free asset is 1 . The supply of risk free assets is infinite. The risky asset pays an uncertain dividend per unit at period $t$ denoted by $d_{t}$. 
The assumption is that the dividend follows an exponential process which is commonly used on measuring dividend growth in finance (Asmussen et al. 2000; Albrecher et al. 2005; Avanzi, 2009). Therefore, the dividend $d_{t}$ is a continuous random variable with the probability density function of an exponential distribution as

$$
h(x)= \begin{cases}\beta e^{-\beta x} & x>0 \\ 0 & x \leq 0,\end{cases}
$$

where $\beta>0$. The supply of the risky asset at time $t$ is constant and is normalized to 1. The price of the risky asset per unit at time $t$ is $p_{t}$, which is determined by market clearing.

Agents in this market are mutual fund managers and their investors. Managers make investment decisions and recommend them to their investors. Investors choose a fund manger to follow according to their past performances. Fund managers refer to both the individuals who direct fund management decisions and the companies which provide investment management services. Investors can be private investors, corporations, pension funds, charities, insurance companies and so on.

We assume that the set of managers is $m$ and the set of investors is $n$. Manger $k \in$ $m(|m|=M)$ is hired by a set of investors $I_{k, t} \subseteq n(|n|=N)$ at period $t . A_{i, t}^{I}$ is the asset of investor $i$ at period $t$. Thus, the total assets managed by manager $k$ at period $t$ is

$$
A_{k, t}=\sum_{i \in I_{k, t}} A_{i, t}^{I}
$$

We also assume that the overall assets from all the investors are fixed as $A$.

\subsection{Market Clearing Price}

In period $t$, on the one hand, fund manager $k$ selects a portfolio $\left(1-y_{k, t}, y_{k, t}\right), y_{k, t} \in[0,1]$ according to his objective. $y_{k, t}$ denotes the fraction of risky assets. This portfolio is recommended to all the investors who follow him. On the other hand, investors follow the recommendation of their managers in a way of investing a fraction $y_{k, t}$ of assets to the risky assets. The payoff of investor $i$ in period $t$ is $y_{i, t}^{I}$, which is given by

$$
y_{i, t}^{I}=y_{k, t} .
$$


The individual demand function for risky assets is determined by the payoff of investor $i$ and his assets in the previous period,

$$
D_{i, t}=\frac{A_{i, t-1}^{I} y_{i, t}^{I}}{p_{t}}
$$

where $A_{i, t-1}^{I}$ is the amount of the assets owned by investor $i$ in previous period $t-1$. Because the supply of risky asset is normalised to 1, market clearing gives the market equilibrium pricing equation as

$$
p_{t}=\sum_{i \in n} y_{i, t}^{I} A_{i, t-1}^{I}
$$

The computation of the market equilibrium shows in Appendix B.

\subsection{The Objective of Fund Manager}

The objective of mutual fund manager is motivated by his compensation contract with clients. In industry practice, asset-based scheme is commonly used to compensate management. It is usually linearly depend on the value of managed assets (Deli 2002. Palomino 2005). We assume that the payment to management is proportional to the amount of managed assets,

$$
C_{k, t}=c_{k, t} A_{k, t}
$$

where $c_{k, t}$ is trader fee per unit of managed asset. However, over the past few years, a few well-known mutual fund companies have started to use performance-based incentive contract. The analysis of both asset-based and performance-based fees appears to be an important task. In this paper, we investigated the dynamic behaviour of market under these two types of compensation schemes. We assume that managers are myopic and make investment decisions only by forecasting the next one period. This makes fund mangers become two types: Asset maximiser and Return maximiser.

Asset Maximiser Motivated by the asset-based compensation, asset maximiser aims to maximise the expected overall assets he manages, even when his objective is not aligned with investor's welfare. Therefore, mutual fund manager's recommend payoff 
is derived from a maximisation problem of the amount of expected assets he manages in the following period, which is $\max _{y_{k, t}} \hat{A}_{k, t+1}$. The maximisation problem is

$$
y_{k, t}=\underset{y_{k, t}}{\operatorname{argmax}} \hat{A}_{k, t+1}
$$

Return Maximiser Return maximiser type of fund manager is motivated by the performance-based compensation contract. He shares the same goal as his clients that he aims to maximise the return of his portfolios. Like asset maximiser, his recommend payoff $y_{k, t}$ is derived from the maximisation problem of his expected objective in the following period, which is the expected return of the portfolio, $\max _{y_{k, t}} \hat{R}_{k, t+1}$. The maximisation problem is

$$
y_{k, t}=\underset{y_{k, t}}{\operatorname{argmax}} \hat{R}_{k, t+1}
$$

\subsection{Fund Selection By Investors}

\subsubsection{The Signal}

The whole point of fund manger is to leave the investment management function to the professionals. Most investors do not have the knowledge or the time to observe the distribution of portfolio and monitor their fund managers. They always choose their managers by observing the publicly available signals. These signals are mostly attached with fund managers' performances. Therefore, managers with better performances always attract more followers. In this model, signal $U_{i, k, t}$ is observed by investors. It is evaluated as the fund managers' performance $P_{k, t}$ subjects to individual investor's error $\delta_{i, k, t}$ :

$$
U_{i, k, t}=P_{k, t}+\delta_{i, k, t}
$$

where $\delta_{i, k, t}$ follows a heavy side distribution.

The managers' performance $P_{k, t}$ is measured by the net realised profits as proposed by Markowitz (1952).

$$
P_{k, t}=R_{k, t}-c, c>0
$$


where $c$ represents the trader fee per period incurred by managers, such as the cost of gathering information. More sophisticated strategies require higher costs. $R_{k, t}$ represents return rate which is defined by using asset pricing model:

$$
R_{k, t+1}=\left(1-y_{k, t}\right) r+y_{k, t}\left(\frac{p_{t+1}-p_{t}}{p_{t}}\right)+\frac{y_{k, t} d_{t+1}}{p_{t}},
$$

where $R_{k, t+1}$ denotes the return rate of the asset from period $t$ to period $t+1$. $p_{t}$ is the price of this asset in period $t$ and $d_{t+1}$ is the dividend paid at the beginning of period $t+1$. The first and the second terms on the right side represent the capital gain of risk free assets and risky assets. The third term is the dividend yield.

\subsubsection{Fund Selection}

Investors choose their managers by observing publicly available signal $U_{i, k, t}$ which is attached with fund managers' performance $P_{k, t}$. Manager with better performance delivers stronger signal to investors. Thence, they attract more clients. We assume that the probability for manager $k$ to be chosen by an investor in period $t+1$ is given by:

$$
n_{k, t+1}=\frac{\exp \left(\lambda P_{k, t}\right)}{Z_{t}}, Z_{t}=\sum_{k=1}^{M} \exp \left(\lambda P_{k, t}\right) .
$$

$Z_{t}$ is a normalisation factor, so that the fraction $n_{j, t}$ adds up to 1 . The rule is that investors tend to choose the manager who has performed well in the most recent past. This picking rule follows a well-known discrete choice model with multinomial logit probabilities. It describes a typical agent chooses an alternative out of a set with a finite number of alternatives. There are several examples in a series of papers as McFadden (1973), McFadden and Reid (1975), etc..

An important parameter $\lambda$ is the sensitivity of choices. It measures how sensitive the investors are, regarding the choice of optimal strategy. It is inversely related to the variance of the noise terms $\delta_{t}$. One extreme case $\lambda=0$, corresponds to infinite variance noise, so that differences in fitness cannot be observed and all fractions will be fixed over time. Investors would distribute themselves evenly across the set of available managers. On the contrary, if $\lambda$ is infinite, it corresponds to the case without noise, so that the deterministic part of the fitness can be observed perfectly. In each period, all traders choose the optimal forecast. In our case, all investors choose the manager with best performance. 


\subsubsection{Inertia Parameter $\kappa$}

Due to the cost of changing manager, sometimes investors may choose to stick to his previous managers or wait for a few periods before switching, even though the public information suggests the optimal strategy is to switch to a new one. Inertia parameter $\kappa$ describes this behaviour. An investor sticks to the manager he followed in previous period with probability $\kappa$. Thus, with probability $1-\kappa$ he considers to switch and select a manager $j \in m(|m|=M), j \neq k$. Therefore, the probability of an investor follows a manager is

$$
\begin{aligned}
\mathrm{P}(\text { stay with manager } k) & =(1-\kappa) n_{k, t}+\kappa \\
\mathrm{P}(\text { switch to manager } j) & =(1-\kappa) n_{j, t}
\end{aligned}
$$

In the special case of $\kappa=0$, every investor updates strategy and switches to a new manager; The more general case $0 \leq \kappa \leq 1$, gives some persistence or inertia in the impact of strategies. Reflecting the fact that not all the investors update their choices every period. $\mathcal{k}$ may be interpreted as the average per period fraction of investors who stick to their previous managers. In the extreme case of $\kappa=1$, they would all stay with previous managers.

\subsection{The Trading Strategy of Fund Manager}

\subsubsection{Adaptive Expectation}

In nonlinear economic models, expectations play an important role. People form their expectations about what will happen in the future based on what has happened in the past. For instance, the behaviour of price in the past periods will influence the people's expectation on price in the future. Early paper of Nerlove (1958) first proposed the model of adaptive expectation formation of future prices. Many papers on Learningto-forecast experiments in Hommes et al. (2005, 2011, 2013) observed the individuals' forecasting behaviour in the laboratory. They all found the evidences of bounded rational and non-fundamental forecasting rules. They also suggested that agents tend to use simple linear rules, in particular trend extrapolating rules.

In this paper, we assume that fund managers are boundedly rational. They are technical traders who use last observed price as an anchor and extrapolate future prices. 
Two classes of trading strategies are being observed: trend chaser and contrarian. These managers believe that they can influence market prices $p_{t}$. The expectation of fund manager on prices in the next period is

$$
\hat{p}_{t+1}=p_{t}+\eta\left(p_{t}-p_{t-1}\right), \eta \in \mathbb{R} .
$$

When $\eta>0$, manager behaves as a trend chaser and expects price changes to continue in the same direction. He buys assets when prices increase and sells them when prices drop. Brock and Hommes (1998) found that trend chasers trigger irregular switching between "optimism" and "pessimism". Market price fluctuates between temporary growing above efficient-market hypothesis(EMH) fundamental with speculative bubbles and falling below the fundamental. When $\eta<0$, manager is a contrarian trader who expects a reversal of the latest prices change. He sells assets when prices increase and buys them when prices decrease. Some empirical evidences suggested that contrarian strategies generate significant abnormal returns over a long period, such as Fama and French (1998), Capaul et al. (1993), Brock and Hommes (1998) showed that contrarians cause a lot of irregular, up and down fluctuations around the fundamental. In particular, when $\eta=0, \hat{p}_{t+1}=p_{t}$, manager is with naive expectation and simply uses the last observed price. This is initially proposed by Ezekiel (1938).

\subsubsection{Optimial Strategy}

In each period, investors are allowed to switch their managers depending on the updated signal of fund managers' performance. In principle, they always switch to the managers with stronger signals. However, we should note that their behaviours are also effected by the inertia parameter $\kappa$. In this paper, we consider the optimal portfolio choice of manager $j$ at period $t$. He assumes that all other managers stick to their portfolios from the previous period as $\hat{y}_{k, t}=y_{k, t-1}$.

From the above notation, the market clearing equation (5) is rewritten as

$$
p_{t}=\sum_{k \neq j}^{M}\left(y_{k, t-1} A_{k, t-1}+y_{j, t} A_{j, t-1}\right)+\epsilon .
$$

To facilitate the computation, we add noises $\epsilon$ to prices. $\epsilon$ is positive but very close to 0 . Under this assumption, there are always investors buying the risky assets so that $p_{t}$ 
stays positive over time. Therefore, the portfolios $\left(1-y_{j, t}, y_{j, t}\right)$ recommended by fund manager $j$ is chosen by the way of optimising his expected compensation. His portfolios may vary with different compensation contracts. In this case, the types of compensation contracts play a key role on the fund manager's optimal strategy.

Motivated by their compensation contract, Asset Maximiser aims to maximise the overall assets he managed. His payoff $y_{j, t}$ is derived from the maximisation problem as

$$
y_{j, t}=\underset{y_{j, t}}{\operatorname{argmax}} \hat{A}_{j, t+1} .
$$

According to Equation (13), the expected assets are

$$
\hat{A}_{j, t+1}=\kappa A_{j, t}+(1-\kappa) A \hat{n}_{j, t+1} .
$$

$\operatorname{Max}_{y_{j, t}} \hat{A}_{j, t+1}$ is thus achieved by $\max _{y_{j, t}} \hat{n}_{j, t+1}$. This is easily understood on intuition. In order to maximise the managed assets, fund manager has to attract as many investors as possible. According to Equation (11), (12) and (14), the portfolio of asset maximiser in period $t$ is derived from the maximisation equation

$$
y_{A, t}=\underset{y_{j, t}}{\operatorname{argmax}}\left\{\int_{0}^{\infty} \frac{\beta}{\sum_{k=1}^{M} \exp \left[\lambda\left(y_{j, t}-y_{k, t-1}\right)\left(r-\frac{\eta\left(\hat{p}_{t}-p_{t-1}\right)+x}{\hat{p}_{t}}\right)+\beta x\right]} d x\right\} .
$$

Following the same idea, Return Maximiser is motivated by performance-based contract. The fraction of risky assets in his portfolio $y_{j, t}$ is derived from the maximisation problem of expected return,

$$
y_{j, t}=\underset{y_{j, t}}{\operatorname{argmax}} \hat{R}_{j, t+1} .
$$

According to equation (11) and (14), the portfolio of return maximiser is

$$
y_{R, t}=\underset{y_{j, t}}{\operatorname{argmax}}\left\{\left(1-y_{j, t}\right) r+y_{j, t}\left[\frac{\eta\left(\hat{p}_{t}-p_{t-1}\right)}{\hat{p}_{t}}\right]+\frac{y_{j, t}}{\beta \hat{p}_{t}}\right\} \text {. }
$$

\section{Maximisation analysis}

In this model, fund managers are either motivated by performance-based contract or by asset-based contract. The managers who are under performance-based contract are 
Return Maximisers. They make payoffs by maximising the portfolios' expected returns, which is $\max \hat{R}_{t+1}$. The managers who are motivated by asset-based contract are Asset Maximisers. They maximise the whole asset they manage and further maximise the probability of investors following them, which is max $\hat{n}_{t+1}$. Moreover, we assume that these managers are boundedly rational with respect to their price expectation. They are distinguished between Trend Chasers and Contrarian Traders.

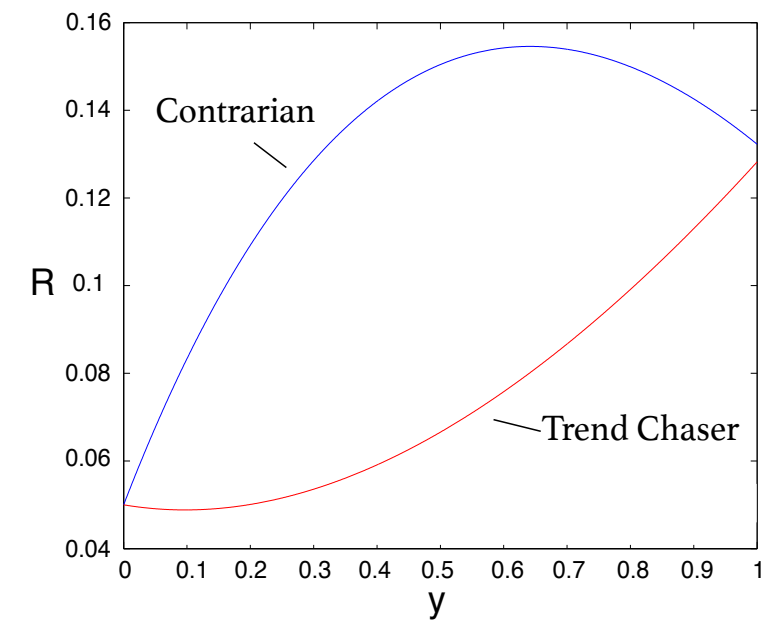

(a) Return maximiser

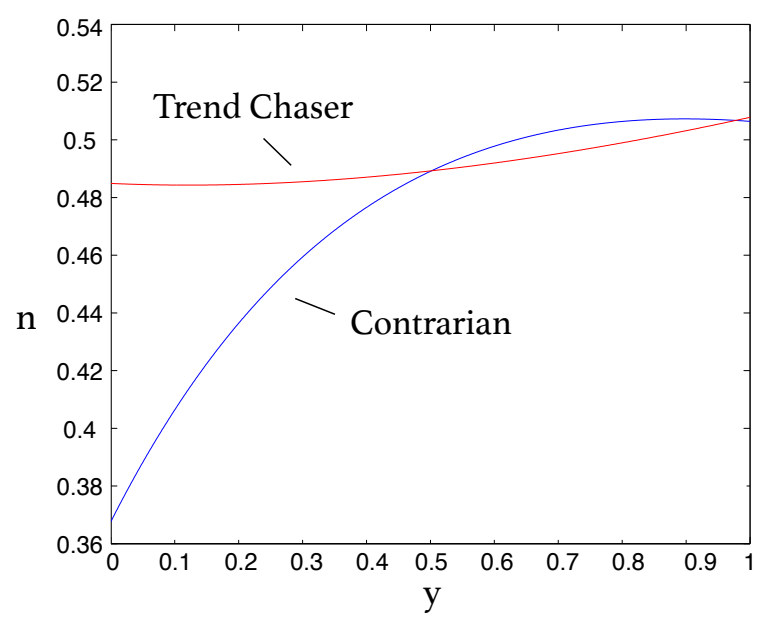

(b) Asset maximiser

Figure 1: The relationship between fund manager's payoff and the objective he makes effort to maximise. (a) The relationship between the payoff of return maximiser and the fund's returns; (b) The relationship between the payoff of asset maximiser and the possibility of investors to follow asset maximiser.

Figure 1 illustrates the relationship between fund manager's payoff and the objective he maximises. Return maximiser aims to maximise his portfolio's returns, while the objective of asset maximiser is to attract as many investors as possible to follow them. For both return maximiser and asset maximiser, their optimal portfolios present similar patterns with respect to adaptive expectations. When the manager is a trend chaser, with $\eta>0$, the relationship between the choice of risky asset's fraction and fund manager's maximisation objective is convex parabola. Thence, for both return maximiser and asset maximiser, they always recommend extreme portfolios to their investors, such as $y=0$ or $y=1$, depending on the parameters. For manager with contrarian expectation, 
$\eta<0$, the choice of risky asset's fraction and the objective is in a concave relationship. His objective can be fulfilled with risky asset's fraction in anywhere between 0 and 1 by changing the parameters. Therefore, he exhibits a behaviour less extreme compared with trend chaser. To sum up, fund manager does alter his risk taking behaviour in the financial market. The adaptive expectations on future price plays a key role. Even under different types of compensation contracts, fund manager always recommends a portfolio in response to his adaptive expectations on the trend of future asset prices. Therefore, in the following, we are going to analysis the optimal choices of fund managers' contracts depends on the types of adaptive expectations.

\section{Simulation Results}

Unless stated otherwise, we use the following baseline parameter values in the simulations:

- The number of investors and managers are $N=10$ and $M=2$. In one type market, all the managers are same type. In two types of market, each manager represents one type.

- In order to avoid widely fluctuations of market, we keep the parameters of managers' adaptive expectation in the range of $-1<\eta<1$. They are $\eta=0.5$ for trend chaser and $\eta=-0.5$ for contrarian trader.

- The average costs per period of managers is $c=0.1$, the parameter in the density of risky asset's dividend is $\beta=0.5$, inertia parameter is $\kappa=0.5$, the sensitivity of investor's choice is $\lambda=0.9$.

A summary of the main notations used in the paper is provided in Appendix A In the dynamic analysis, each simulation runs for $T=100$ periods.

\subsection{One type market}

\subsubsection{Dynamics under one type market}

In this section, we analysis a homogenous market with one type of fund manager as a benchmark. The assumption is that all managers use a same strategy. Based on 
the type of adaptive expectation and compensation schemes, there are four sorts of managers (see Table 1): Trend chaser under asset-based compensation schemes, trend chaser under performance-based compensation schemes, contrarian trader under assetbased compensation schemes, contrarian trader under performance-based compensation schemes. Meantime, investors choose fund managers according to their performance in the past and are also allowed to update their choices over time.

Table 1: Types of fund managers

\begin{tabular}{|l|c|cc|}
\hline \multicolumn{2}{|c|}{} & \multicolumn{2}{|c|}{ Compensation schemes } \\
\cline { 3 - 4 } \multicolumn{2}{|c|}{} & Asset-based & Performance-based \\
\hline \multirow{2}{*}{ Adaptive expectations } & Trend Chaser & I & II \\
& Contrarian & III & IV \\
\hline
\end{tabular}

I. Trend chaser and Asset maximiser; II. Trend chaser and Return maximiser;

III. Contrarian trader and Asset maximiser; IV. Contrarian trader and Return maximiser.

Figure 2 presents the dynamic behaviours of the market prices, the fund managers' payoffs and the funds' returns in each market. As shown in Figure 2(a), the market prices are driven by the different expectation schemes. When fund managers use the trading strategy of trend chaser, the market exhibits highly irregular switchings of prices; If fund managers use strategy of contrarian, market up and down oscillations. This is the case whenever fund managers are under asset-based or performance-based contract. Brock and Hommes (1998) also found that the presence of trend chasers or contrarians may lead to market instability and chaos. In particular, trend chasers trigger irregular and unpredictable switching between the phases of "optimism', with prices following temporary speculative bubbles, or "pessimism", with prices falling bellow the fundamental. Contrarians cause a lot of irregular, up and down oscillations around fundamental.

Figure 2(b) illustrates the dynamic behaviour of the fund managers' choice of the fraction of risky assets $y$. It also exhibits highly fluctuations in the market with trend chasers and small oscillations in the contrarian case. This is consistent with market prices in Figure 2(a). The intuition is that the expectation of trend chasers always drive 
them to make extreme payoffs every few periods. For instance, if market prices increase in one period, trend chasers would expect the prices keep changing in the same direction in the future. They would raise the fraction of risky assets in their portfolios in the next period. In one type market, all the managers behave in the same way that they are all buying the risky assets. Therefore, the prices keep increasing and managers will raise their risk levels further. In this way, after several periods, managers' payoffs will become fully risky. On the contrary, if market prices dropped, they presume another decline and cut back the fraction of risky assets. The portfolios will have no risk at all after a few periods. The returns of portfolios also exhibit consistent dynamic behaviours with market prices and payoffs (see Figure 2(c)). Very high returns can be generated by some portfolios of trend chasers due to highly risk taking behaviour. However, their returns are unstable over time.

We should note that although the types of compensation contracts do not have as much impact as expectations to trend chasers, they do make differences when it comes to the market with contrarians. When these contrarians are asset maximisers and under asset-based contract, they tend to recommend risky portfolios as shown in Figure 2(b). Compared with return maximisers, the prices in their markets are higher. Their portfolios give lower returns over time. When contrarians are under performance-based contract, they decrease their risky levels. In the end, return maximisers achieve higher returns than asset maximisers.

In general, our analysis shows that the fund managers' adaptive expectations affect the stability in the market. Both of trend chasers and contrarians fail to stabilise the market. Trend chasers tend to trigger highly fluctuations of the market. This influence are equally effective under both asset-based and performance-based contract. We also observe the influence of different types of compensation contracts and find that they change the risk taking behaviours of contrarians. The asset-based contract induces more risky portfolios, while the performance-based contract motivates the portfolios with higher returns.

\subsubsection{The impact of inertia parameter $\kappa$}

In the previous section, we investigate the dynamic of one type market with a benchmark inertia parameter $\kappa=0.5$. It stands for the probability that an investor sticks to his previous manager is 0.5 . Because there is only one type of fund manager in the mar- 
ket, inertia parameter plays an important role on the choices of investors. Regarding this, the impact of the changes of inertia parameter $\mathcal{k}$ on the dynamic behaviour of the market is of particular interest. To exclude other influences, such as the impact from expectation parameter $\eta$, we analysis different homogenous markets individually. In order to trace the impact of the changes of $\kappa$ to market dynamic behaviours, we refer to four cases of $\kappa$, which are $\kappa=0,0.5,0.8$ and 1 .

\subsubsection{Contrarians}

Figure 3 shows the dynamics of prices $p$ (Figure $3 \mathrm{a}$ ), the fund managers' payoffs $y$ (Figure $3 \mathrm{~b}$ ) and the returns of portfolios $R$ (Figure $3 \mathrm{k}$ ) in the market with one type of fund managers. These fund managers are with contrarian expectation on the future prices. Moreover, they are under performance-based compensation contract that their objective is to maximise the return of portfolios. To compare, each figure gives simulated time series with respect to $\kappa$ equals to $0,0.5,0.8$ and 1 .

In previous section, we showed that the market with contrarian traders was more stable than the market with trend chasers. However, as we shall see in these figures, the slightly up and down oscillations are amplified by raising the inertia parameter $\kappa$. When $\kappa$ is increasing from 0 to 0.5 , a manager tends to increase the risk level of his portfolios and raises the prices in the market. In particular, if $\kappa$ is high, such as over 0.8 , we observe significant changes of the portfolios' risk levels in different periods. In some periods the manager would recommend complete riskless portfolios to investors while on the other times he may recommend highly risky ones. This behaviour makes the market prices irregular fluctuation dramatically. We should note that the managers in this market are also return maximisers and aim to optimise the returns of their portfolios. However as show in Figure 3(c), with the increasing of inertia parameter, the returns are decreasing. In this market, when inertia parameter is very high, the returns of the managers' portfolios become very small, even close to 0 . The intuition is that the very small returns may motivate the significant change of fund managers' behaviours either by increasing or decreasing their risk levels dramatically, in order to satisfy their objective of maximising returns.

The dynamic behaviours of a market with only one type of fund managers who are asset maximisers with contrarian expectation are shown in Figure 4 Intuitively, the 
inertia parameter $\kappa$ should not influence the performance of asset maximiser, since his only concern is to optimise the fraction of investors who follow him. However, the dynamics shows that the slightly up and down oscillations of the market are amplified by raising the inertia parameter $\kappa$. Moreover, price are dropping while increasing the level of $\kappa$. It suggests the possible price bias and increasing noises given larger $\kappa$. When $\kappa$ increases, the noise is amplified and price is underestimated. However, no matter $\kappa$ changes or not, returns remain around the same level. In all, $\kappa$ amplifys fluctuations and make market price to be easily underestimated.

\subsubsection{Trend chasers}

This section investigates a homogenous market with the fund managers with trend chaser type of expectation. Figure 5 shows the analysis of the dynamic behaviour under performance-based compensation schemes. Figure 6 is with same format as Figure 5 and presents the analysis under asset-based compensation schemes.

Consistent with the results in Section 4.1.1. trend chasers trigger irregular and significant fluctuations in the market under both types of compensation contracts. They tend to recommend extreme portfolios, fully risky or complete riskless, during all the range of inertia parameter $\kappa$. Their risk taking behaviours changes significantly over time. Therefore, the market with trend chasers wildly fluctuates under both asset-based and performance-based contracts. The intuition is that trend chasers always change their risk taking behaviours based on their expectations. They expect the prices change in the same direction as it in the past. When prices increase, they raise the risk level of their portfolios because that they expect another increase of the prices in the future. This speculative behaviour raises the market prices and increases managers' risk levels in turn. After several periods, the trend chaser expectation would drive their risk levels to the extremes. Moreover, the influences of trend chaser expectations are so strong that it dominates the dynamic behaviours of the market over time. Fund managers only concern chasing the change of price. The influence of compensation contract can be neglected. Therefore, the dynamics under performance-based and asset-based compensations exhibit similar patterns. 

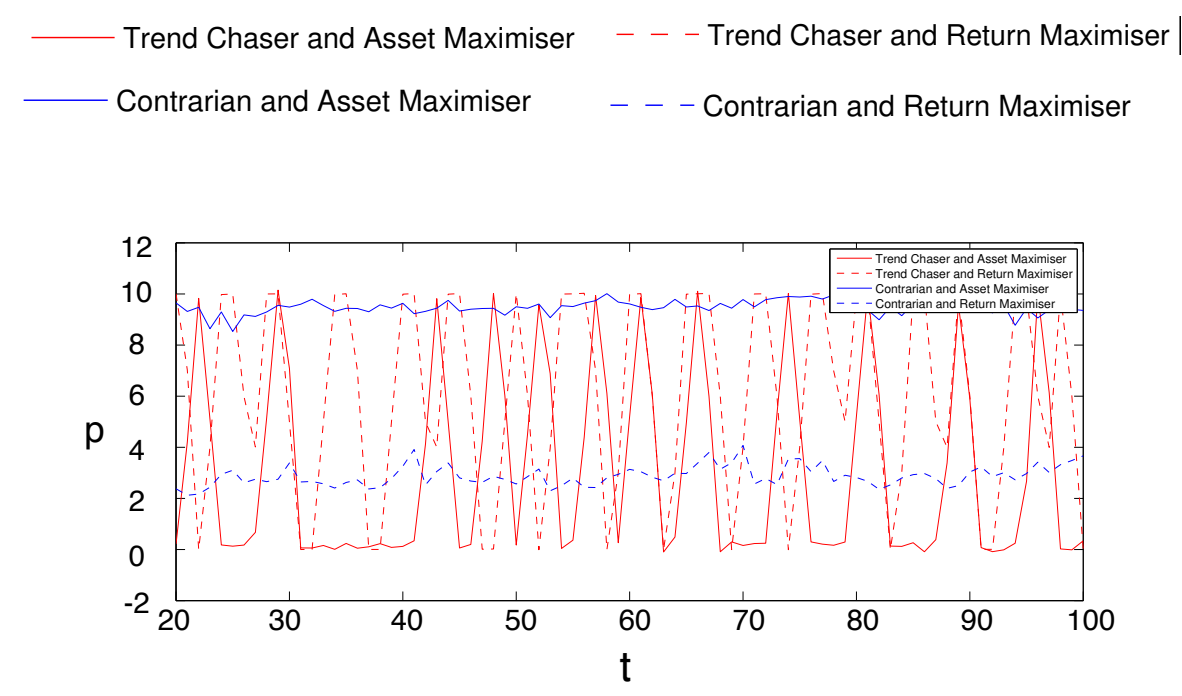

(a) Prices

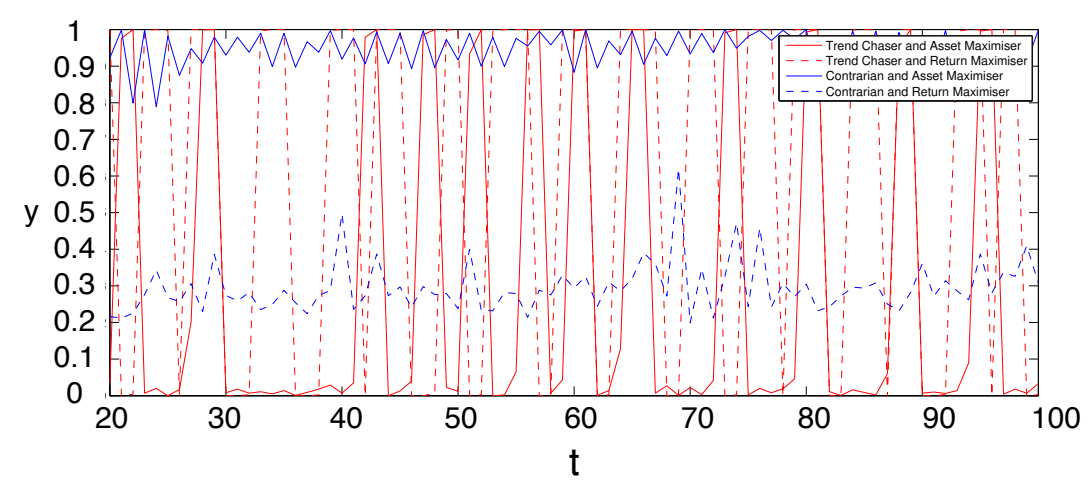

(b) Fraction of risky assets

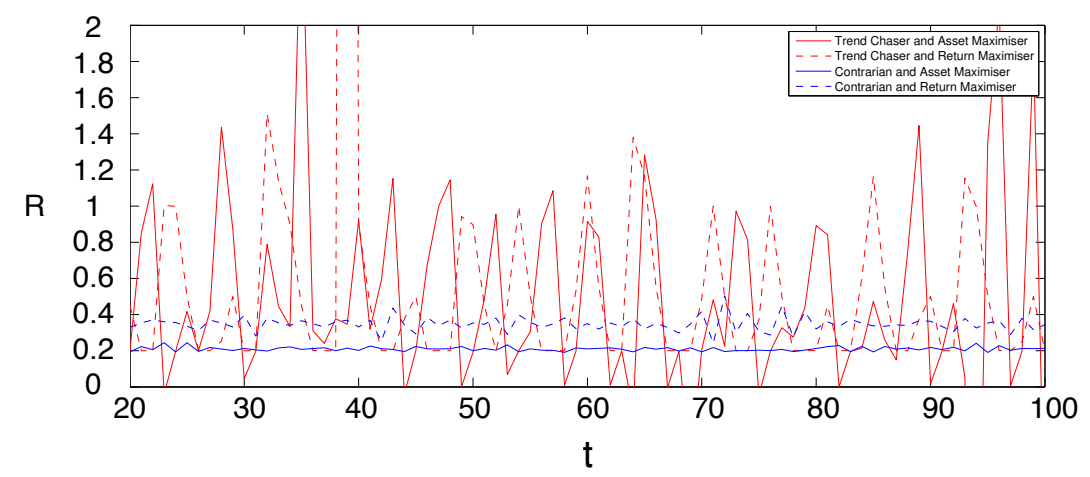

(c) Returns

Figure 2: Dynamics of one type market. (a) Prices $p$; (b) Fund manager's payoffs: the fraction of risky asset $y$; (c) Returns $R$. 


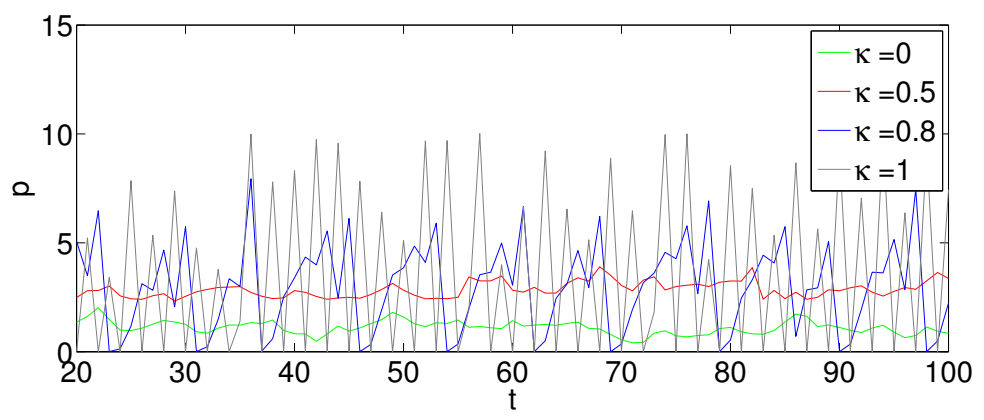

(a) Prices

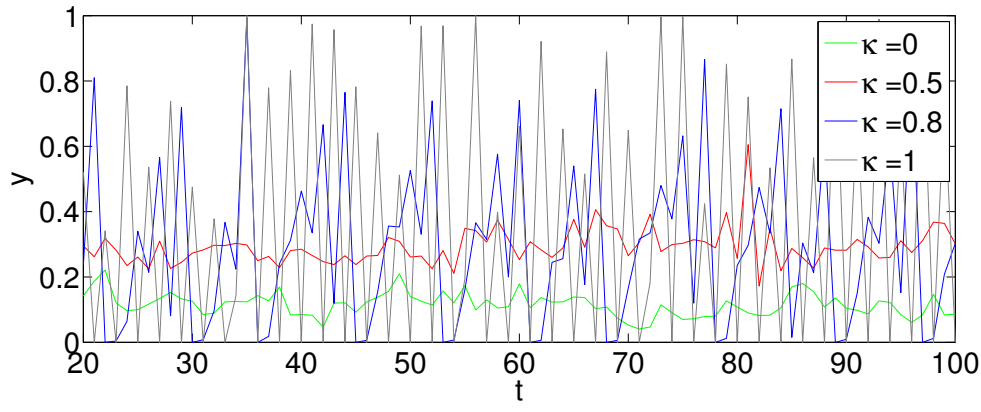

(b) Fraction of risky assets

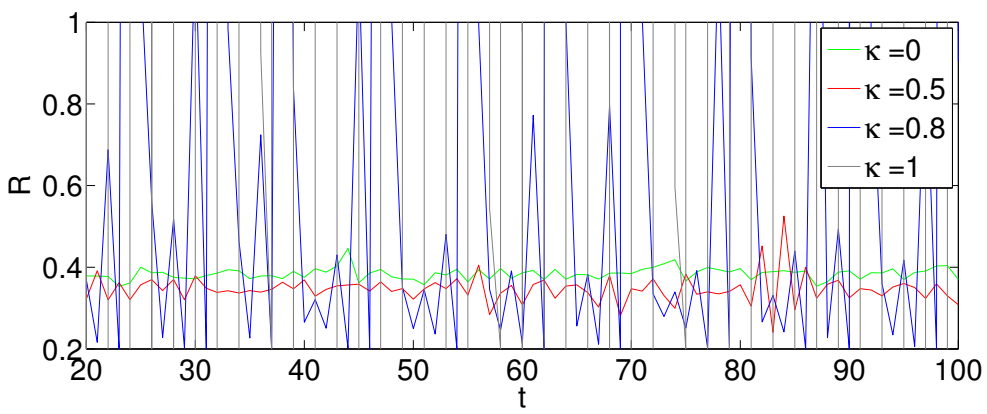

(c) Returns

Figure 3: Dynamics in one type market with the fund managers with contrarian expectation. The fund managers are return maximisers and under performance-based compensation schemes. (a) Prices $p$; (b) Manager's payoffs $y$; (c) Returns $R$. 


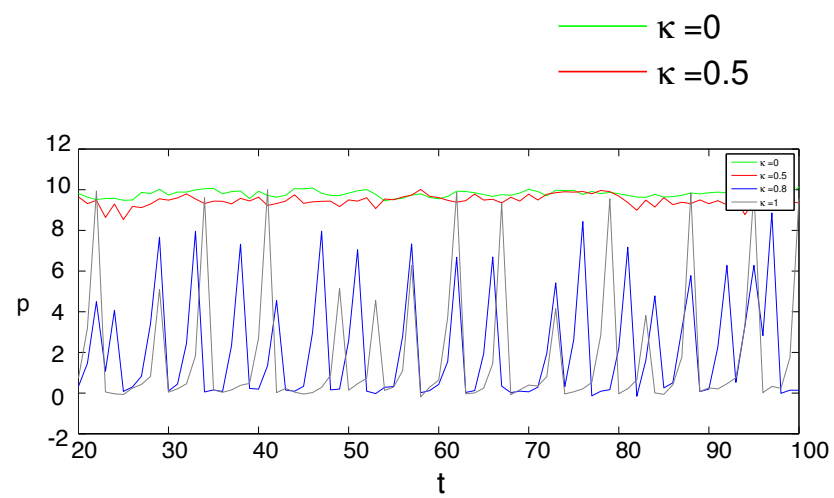

(a) Prices

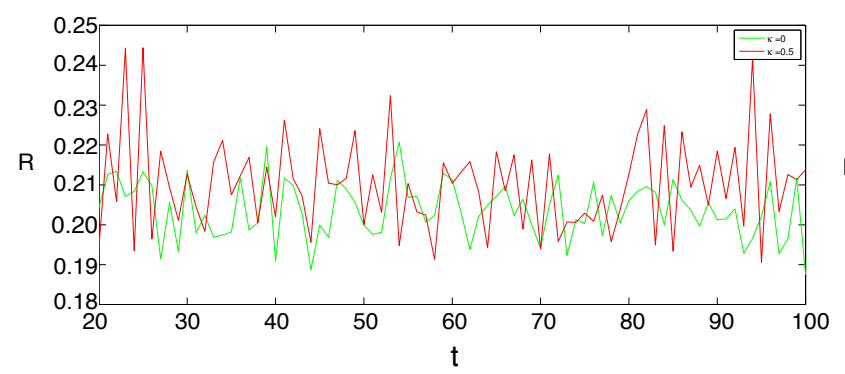

(c) Returns when $\kappa=0, \kappa=0.5$
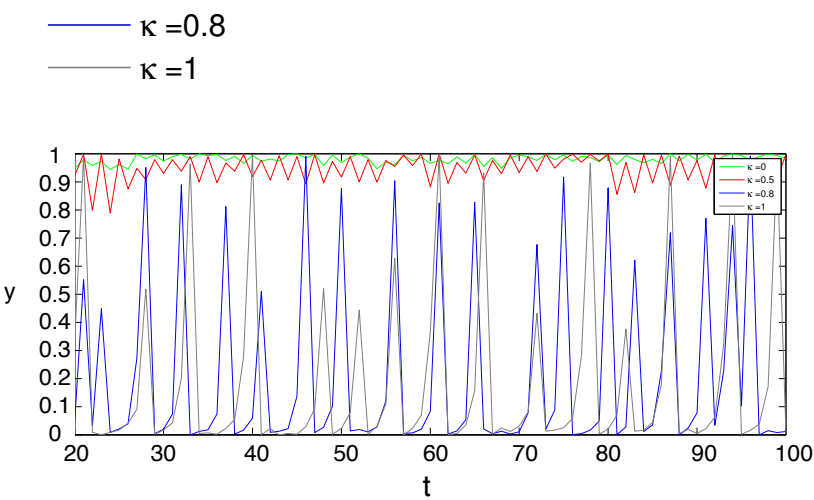

(b) Fraction of risky assets

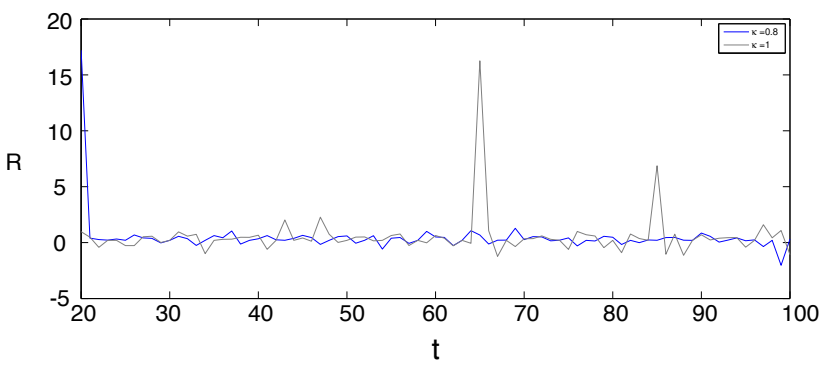

(d) Returns when $\kappa=0.8, \kappa=1$

Figure 4: Dynamic in one type of market with the fund managers with contrarian expectation. These fund managers are asset maximisers and under asset-based compensation schemes. (a) Time series of prices; (b) Time series of the fractions of risky assets; (c), (d) Time series of Returns. 


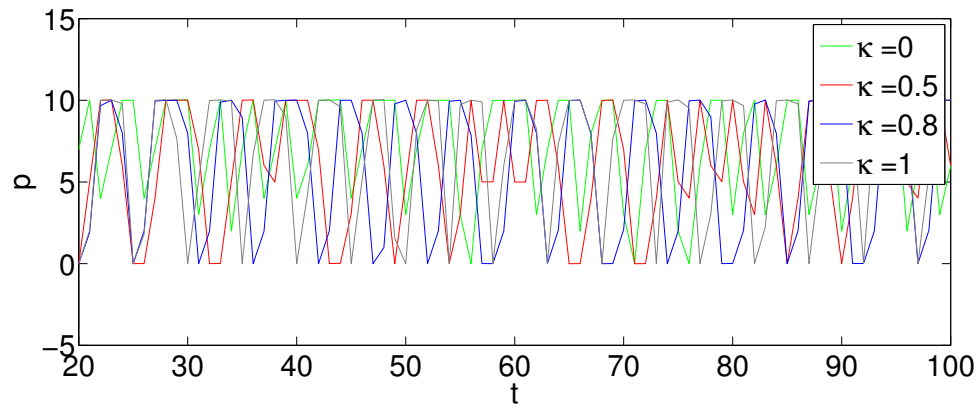

(a) Prices

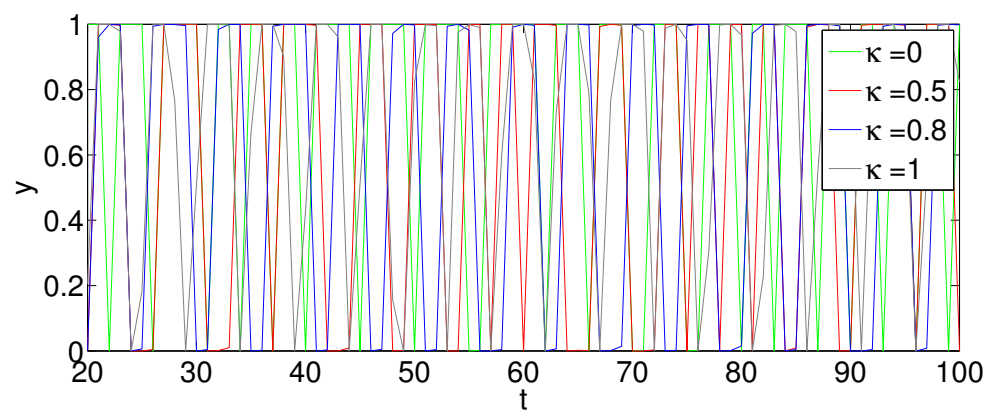

(b) Fraction of risky assets

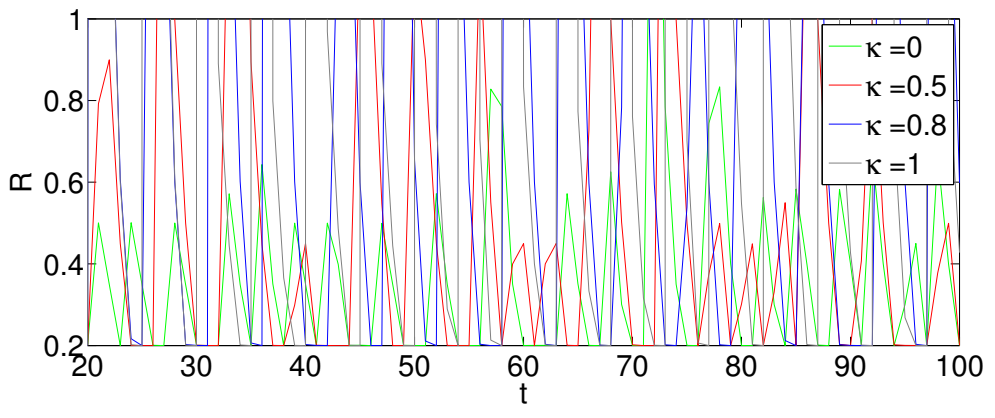

(c) Returns

Figure 5: Dynamic in one type of market with trend chasers and return maximisers. (a) Prices $p$; (b) Payoffs $y$ of managers. (c) Returns of the portfolios 

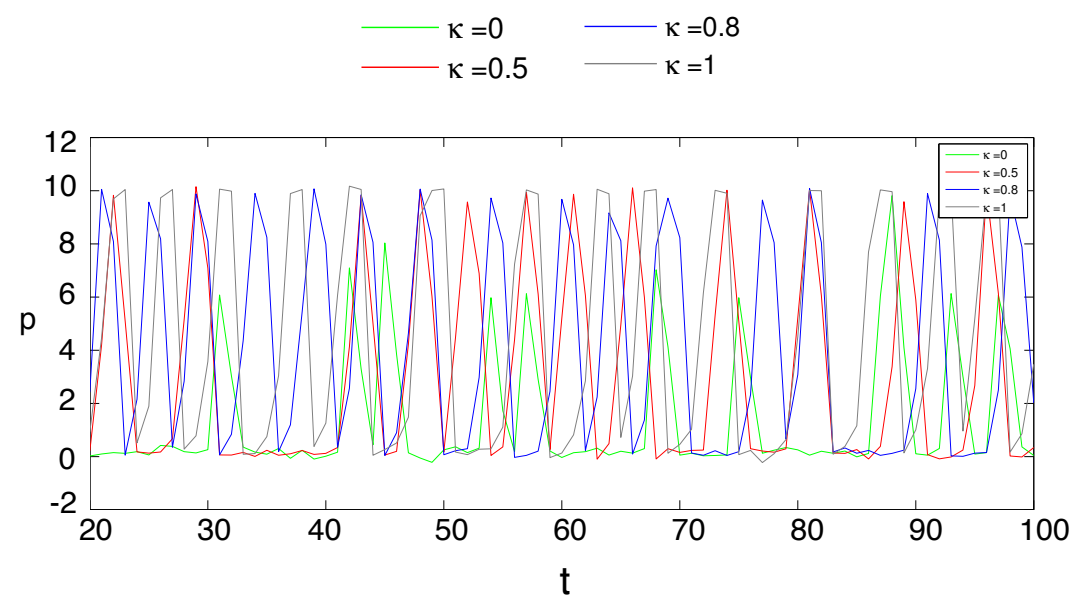

(b) Prices

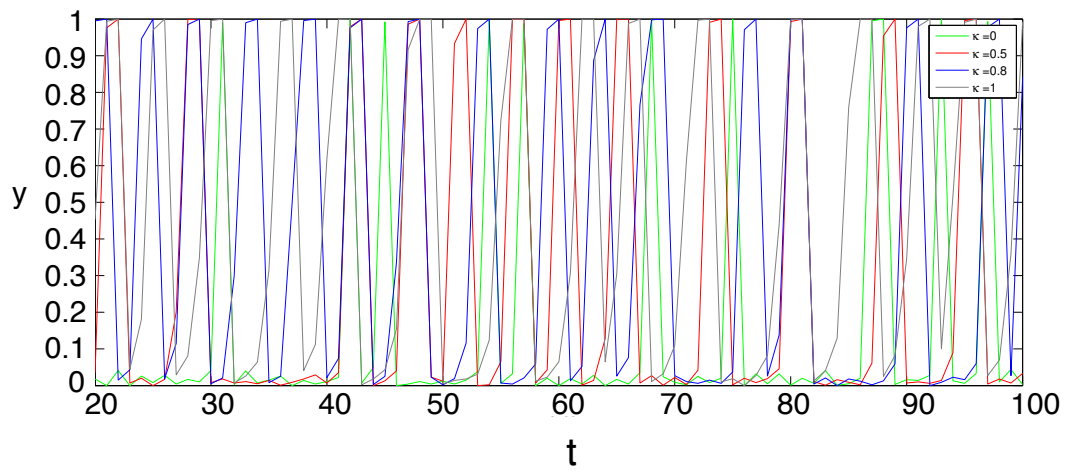

(c) Fraction of risky assets

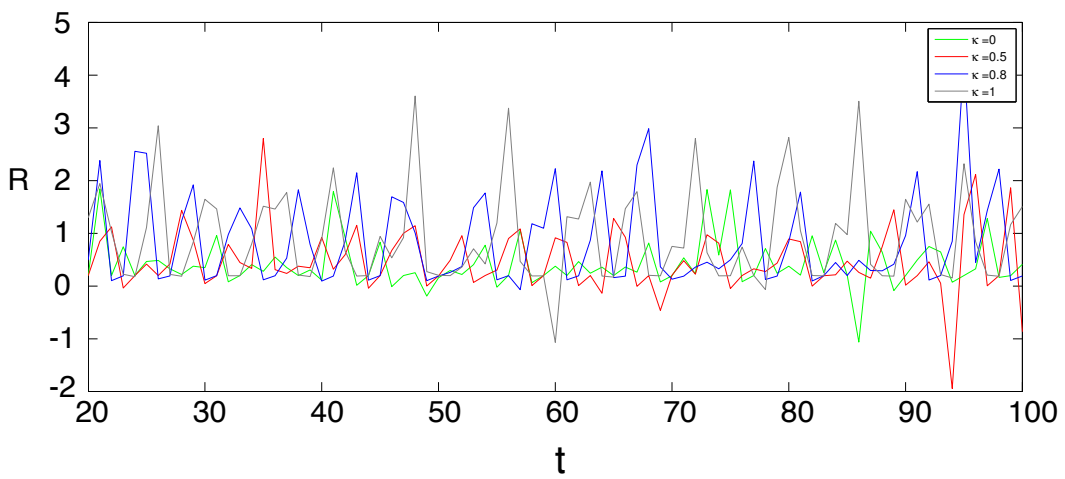

(d) Returns

Figure 6: Dynamic in one type of market with trend chasers and asset maximisers. (a) Prices $p$; (b) fund manager's payoffs $y$; (c) returns $R$. 


\subsection{Two types market}

In previous analysis, we investigated the dynamic behaviours of market with fund managers who are under only one compensation contract. We found some differences between the influence of different compensation contract on different adaptive expectations, and also the influence of inertia parameter. However, in the real market those two compensation schemes are coexistence. Although asset-based schemes are the dominant form of compensation types in the advisory contract between mutual fund manager and investors, increasing number of mutual fund companies have been involving performance-based schemes in their contract. In particular, the larger and more complex companies tend to use more explicit performance-based incentives, due to the fact that they usually face higher direct monitoring costs. In this section, we consider heterogenous types of fund manager, asset maximiser and performance maximiser. Investors switch between these two types of fund managers and are allowed to update their choices over time.

Figure 8 and 7 show the dynamic behaviours of the heterogenous market with the coexistence of return maximiser and asset maximiser types of fund managers under the trading strategies of contrarian and trend chaser. In one type market, fund managers behave distinct adapting two types of adaptive expectations. Trend chasers tend to trigger the significant fluctuations in the market while contrarians bring the up and down oscillations. However, as we shall see, the coexistence of asset maximisers and return maximisers narrows the differences between these two types of trading strategies. The dynamic behaviours of the market under contrarian expectation exhibits similar patterns as the market under trend chaser expectations. Both of them are highly unstable. The prices and the risk level of portfolios fluctuation dramatically. In another words, the coexistence of two types of compensation schemes increase the risk level of contrarians and motivates them to behave very like trend chaser. Boswijk et al. (2007) suggested that stock market bubbles may be amplified by the strategy of trend chasers. There were also several empirical evidences that the relative proportion among forecasting services of trend-following beliefs compared to fundamental mean reverting rules increased in the bubble market (Frankel and Froot, 1987; Vissing-Jorgensen, 2004). Therefore, asset-

based contract may also amplified the stock price bubble by motivating contrarian to behave like trend chaser. 
Intuitively, the higher return should be given by return maximiser since he always aims to optimise fund's return. Nevertheless, on the contrary, in this market the portfolios selected by asset maximisers generate higher returns than performance maximiser, and has significant effect on the average returns of all the portfolios in the market. As shown in the results before, inertia parameter $\mathcal{K}$ would make market price to be easily underestimated. Therefore, the negative bias makes return maximiser give lower optimise returns, while asset maximiser is driven by risk and in turn generating higher returns. The fractions of investors who follow asset maximisers are around 0.9, which leave only around 0.1 of investors to follow return maximisers. Therefore, asset-based schemes become the dominant form of compensation type. However, either types of compensation schemes are able to drive out the other type completely. This is exactly what happens in real financial market. In 1996, 2,190 of 2,351 actively managed equity mutual funds used asset-based management fees whereas only 39 used performancebased fees (Moody, 1996). In recent years, even though performance-based fees have been involved in a lot of larger mutual fund companies, the dominant compensation scheme in the advisory contracts are still based on asset. For example, in 2004, only $9 \%$ of all U.S. mutual funds are under performance-based scheme (Information from Greenwich Associates and the Investment Company Institute).

Our results can be used to explain why a majority of mutual funds favour simple asset-based compensation schemes. This type of contract is able to motivate fund managers use their recourses and expertise knowledges to attract as many assets as possible in the market. Meantime, they also motivates the portfolios with high returns that they contribute to most of the average return in heterogenous market. This contract is able to meet managers' objective and investors' expectations at the same time. Therefore, asset maximisers dominant the whole market and contribute to most of the average returns in the market.

As a complementary, we also observed the market with heterogenous adaptive expectations of trend chaser and contrarian under different types of compensation contracts. These markets are highly unstable and exhibit wildly fluctuations as the dynamics in Figure 8 and 7 . Both of traders coexist with fractions varying over time and prices fluctuating chaotically. Either of the type cannot drive out other trader types and fail to stabilizse price fluctuations toword its fundamental value. In all our examples, the influence of trend chaser is very strong that it always turns oscillations in market 
into unpredictable chaotic fluctuations. The influence of motivation contract can be neglected compared with it.

\section{Asset Maximiser — Return Maximiser — Average Return}

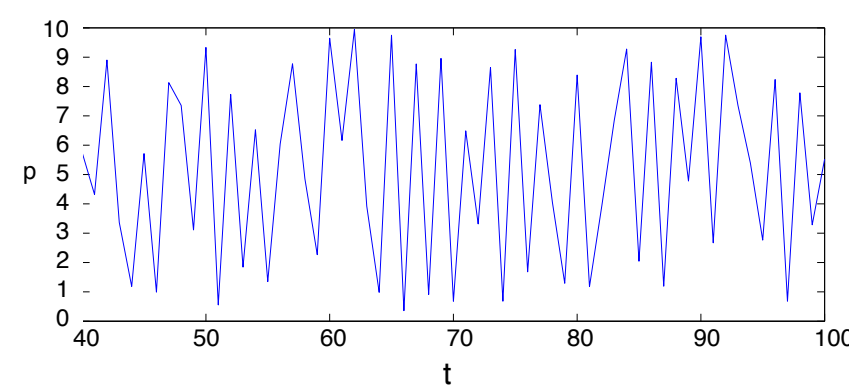

(a) Prices

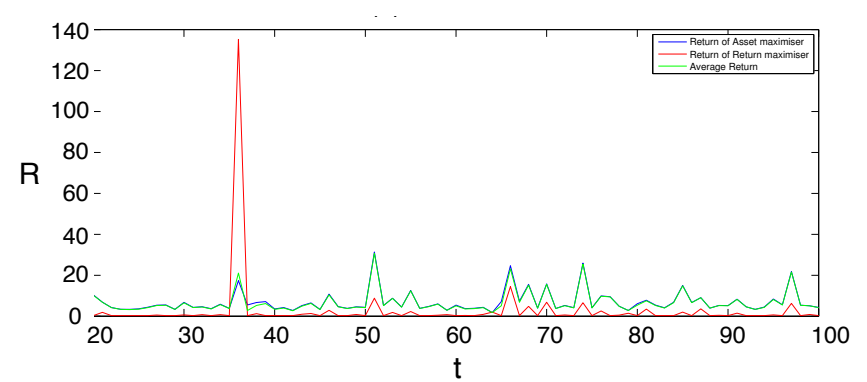

(c) Returns

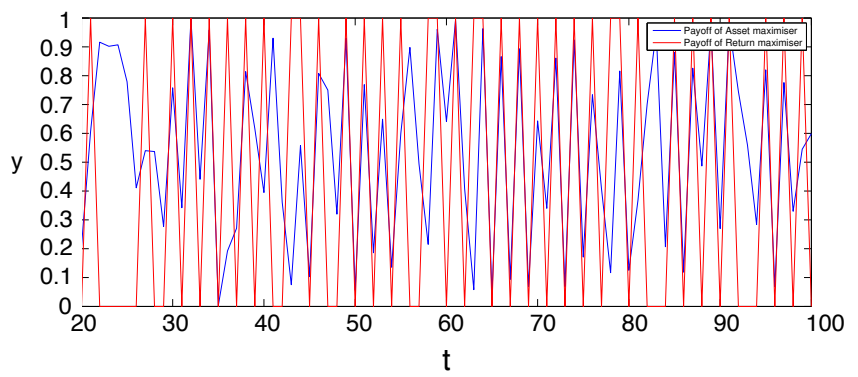

(b) Fraction of risky assets

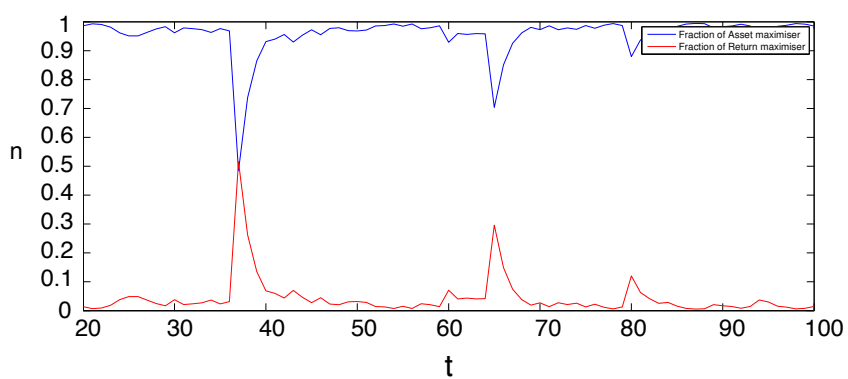

(d) Fractions of the investors

Figure 7: Dynamics in a heterogenous market with return maximisers and asset maximisers. Fund managers are with contrarian expectation.(a) Prices $p$; (b) Payoffs of fund managers $y$; (c) Returns $R$; (d) Fractions of the investors who follow different types of fund managers $n$. 


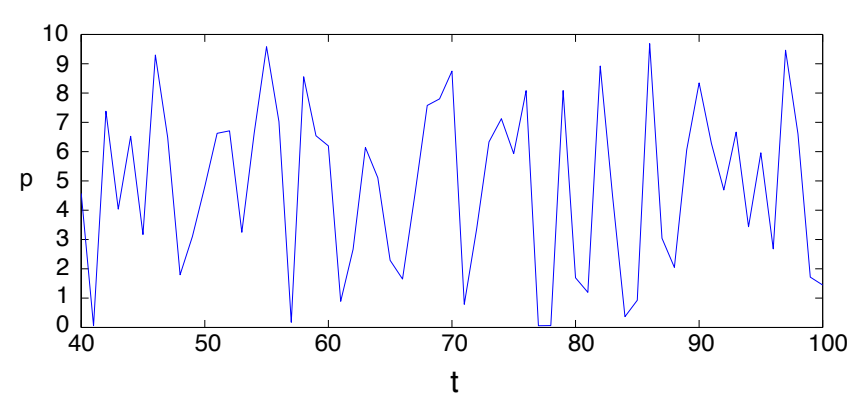

(a) Prices

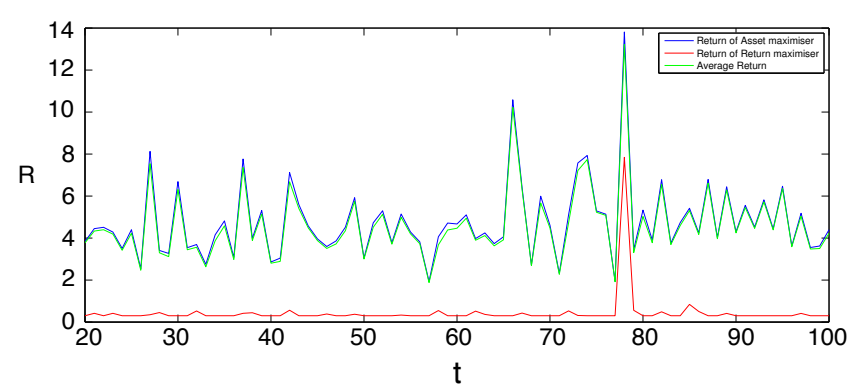

(c) Returns

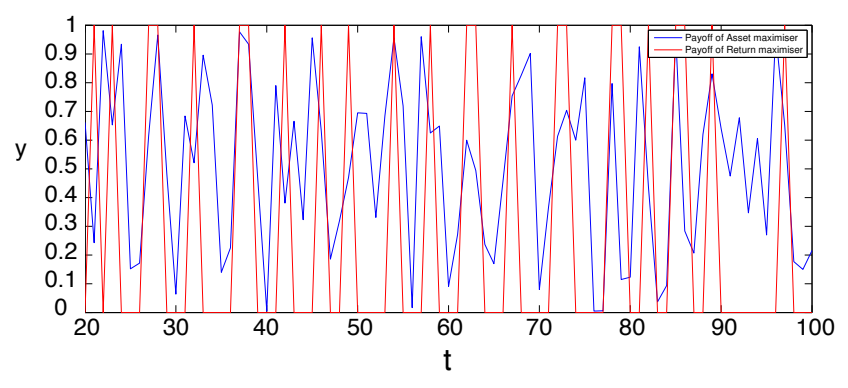

(b) Fraction of risky assets

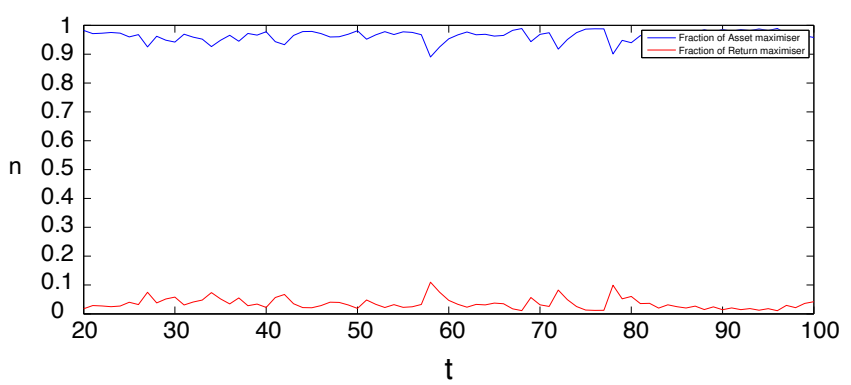

(d) Fraction of the investors

Figure 8: Dynamics in a heterogenous market with return maximiser and asset maximiser. Fund managers are with trend chaser expectation. (a) Prices $p$; (b) Payoffs of fund managers $y$; (c) Returns $R$; (d) Fractions of the investors who follow different types of fund managers $n$.

\section{Conclusion}

In this paper, we established an agent-based model to describe the dynamic behaviours of the financial market with mutual fund managers and investors under two types of compensation contracts: asset-based fees and performance-based fees, using two types of adaptive expectations: trend chaser and contrarian. In our frame work, on the one hand, investors choose their fund managers by observing public available performance measures. The manager with better performance attracts more followers. On the other hand, fund managers are myopic and boundedly rational, using last observed price as an anchor to extrapolate future price. They also motivated by two compensation schemes: asset-based fees and performance-based fees. They motivate fund managers 
behave differently as asset maximisers and return maximisers. We aim to find the link between the types of compensation contract and adaptive expectations.

As a benchmark, we observed homogenous market with only one type of fund managers. The dynamic analysis shows that the adaptive expectations have great impact on the stability of market. Both of trend chasers and contrarian traders make the market less stable. In particular, trend chasers trigger the wildly irregular fluctuations, while contrarians brings along the small up and down oscillations to the market. This is influence is equally effective under both asset-based and performance-based contract. As for the influences from the type of compensation schemes, they do change the risk taking behaviour of contrarian traders. They are willing to take more risk when they are under asset-based contract. However, for trend chaser, they do not care the motivation contract, but only concern chasing the price.

Inertia parameter $\kappa$ also plays an important role in the dynamic behaviours of the market. It destabilises the market and induce market price bias. When $\kappa$ increases, price is underestimated, which makes asset-based compensation scheme generates higher returns in heterogenous market.

In heterogenous market, the coexistence of two types compensation schemes narrows the differences between trend chaser and contrarian markets. They exhibits similar patterns. Contrarian traders behave very like trend chasers that it may amplifies market bubbles. However, in the long run, asset maximisers dominant market. Most of the average returns in the market are contributed by asset maximisers. In particular, under asset-based contract, fund manager is able to maximise his own compensations and generate a high return portfolio at a same time. These results can be used to explain why a majority of mutual fund companies favour simply asset-based compensations schemes.

\section{References}

Albrecher, H., Hartinger, J. and Tichy, R. F. (2005). On the distribution of dividend payments and the discounted penalty function in a risk model with linear dividend barrier. Scandinavian Actuarial Journal, 2005, number 2, 103-126.

Arthur, W.B., Holland, J.H., LeBaron, B., Palmer, R. and Taylor, P. (1997). Asset Pricing 
Under Endogenous Expectations in an Artificial Stock Market, chapter The economy as an evolving complex system II. Addison-Wesley.

Asmussen, S., Hojgaard, B. and Taksar, M. (2000). Optimal risk control and dividend distribution policies. example of excess-of loss reinsurance for an insurance corporation. Finance and Stochastics, 4, number 3, 299-324.

Avanzi, B. (2009). Strategies for dividend distribution: A review. North American Actuarial Journal, 13, number 2, 217-251.

Baumol, W., Goldfeld, S. M., Gordon, L. A. and Koehn, F.-M. (1989). The economics of mutual fund markets: Competition versus regulation, volume 7 . Springer.

Berkowitz, M. K. and Kotowitz, Y. (2000). Investor risk evaluation in the determination and of management incentives in the mutual fund. Journal of Financial Markets, 3, 365-387.

Bines, H. E. and Thel, S. (2004). Investment management law and regulation. Aspen Publishers.

Boswijk, H P., Hommes, C.H. and Manzan, S. (2007). Behavioral heterogeneity in stock prices. Journal of Economic Dynamics and Control, 31, number 6, 1938-1970.

Brock, W.A. and Hommes, C.H. (1998). Heterogeneous beliefs and routes to chaos in a simple asset pricing model. Journal of Economic Dynamics and Control, 22, number 8-9, $1235-1274$.

Capaul, C., Rowley, I. and Sharpe, W. F. (1993). International value and growth stock returns. Financial Analysts Journal, 27-36.

Chevalier, J. and Ellison, G. (1997). Risk taking by mutual funds as a response to incentives. Journal of Political Economy, 105, number 6, 1167-1200.

Chiarella, C. and He, X. (2002). An adaptive model on asset pricing and wealth dynamics with heterogeneous trading strategies. University of Technology.

Cohen, S. I. and Starks, L. T. (1988). Estimation risk and incentive contracts for portfolio managers. Management Science, 34, number 9, 1067-1079. 
Cuoco, D. and Kaniel, R. (2011). Equilibrium prices in the presence of delegated portfolio management. JOURNAL OF FINANCIAL ECONOMICS, 101, number 2, 264-296.

Damato, K. (2005). Funds made math mistakes on performance fees. The Wall Street Journal, C13.

Deli, D. N. (2002). Mutual fund advisory contracts: An empirical investigation. The Journal of Finance, 57, number 1, 109-133.

DeLong, J. B., Shleifer, A., Summers, L. H. and Waldmann, R. J. (1990). Noise trader risk in financial markets. Journal of Political Economy, 98, number 4, 703-738.

Eichberger, J., Grant, S. and King, P. S. (1999). On relative performance contracts and fund and managers incentives. European Economic Review, 43, 135-161.

Evans, G. W. and Honkapohja, S. (2001). Learning and expectations in macroeconomics. Princeton University Press.

Ezekiel, M. (1938). The cobweb theorem. The Quarterly Journal of Economics, 52, number $2,255-280$.

Fama, E. F. and French, K. R. (1998). Value versus growth: The international evidence. The Journal of Finance, 53, number 6, 1975-1999.

Frankel, J. A. and Froot, K. A. (1987). Using survey data to test standard propositions regarding exchange rate expectations. The American Economic Review, 77, number 1, 133-153.

Friedman, D. and Abraham, R. (2009). Bubbles and crashes: Gradient dynamics in financial markets. Journal of Economic Dynamics \& Control, 33, 922-937.

Goetzmann, W. N., Peles, N., William, P. and Goetzmann, N. (1997). Cognitive dissonance and mutual fund investors. Journal of Financial Research, 20, 145-158.

Grinold, R. and Rudd, A. (1987). Incentive fees: who wins? who loses? Financial Analysts Journal, 27-38.

Holmstrom, B. and Milgrom, P. (1987). Aggregation and linearity in the provision of intertemporal incentives. Econometrica: Journal of the Econometric Society, 303-328. 
Hommes, C. H. (2011). The heterogeneous expectations hypothesis: Some evidence from the lab. Journal of Economic Dynamics and Control, 35, number 1, 1-24.

Hommes, C. H. (2013). Reflexivity, expectations feedback and almost self-fulfilling equilibria: economic theory, empirical evidence and laboratory experiments. Journal of Economic Methodology, 20, number 4, 406-419.

Hommes, C. H., Sonnemans, J., Tuinstra, J. and Van de Velden, H. (2005). Coordination of expectations in asset pricing experiments. Review of Financial Studies, 18, number 3, 955-980.

Ippolito, R. A. (1992). Consumer reaction to measures of poor quality: Evidence from the mutual fund industry. Journal of Law and Economics, 35, number 1, pp. 45-70.

Jensen, M. C. and Meckling, W. H. (1976). Theory of the firm: Managerial behavior, agency costs and ownership structure. Journal of Financial Economics, 3, number 4, 305-360.

Malkiel, B. G. (1995). Returns from investing in equity mutual funds 1971 to 1991 . The Journal of Finance, 50, number 2, 549-572.

Markowitz, H. (1952). Portfolio selection. The Journal of Finance, 7, number 1, 77-91.

McFadden, D. (1973). Conditional logit analysis of qualitative choice behavior, zarembka p. Frontiers in Econometrics.

McFadden, D. and Reid, F. (1975). Aggregate travel demand forecasting from disaggregated behavioral models. Transportation Research Record, number 534.

Mendoza, A. C. D. and Sedano, M. . M. (2009). The choice of performance-based fees in the mutual fund industry: the case of spain. Investment Management and Financial Innovations, $\mathbf{6}$.

Moody (1996). Moody's Manuals on Banks and Financial Companies. Moodys Investor Services, New York.

Murphy, K. J. (1999). Executive compensation. Handbook of labor economics, 3, 2485-2563. 
Nerlove, M. (1958). Adaptive expectations and cobweb phenomena. The Quarterly Journal of Economics, 227-240.

Ou-Yang, H. (2003). Optimal contracts in a continuoustime delegated portfolio management problem. Review of Financial Studies, 16, number 1, 173-208.

Palomino, F. (2005). Relative performance objectives in financial markets. Journal of Financial Intermediation, 14, number 3, 351-375.

Patel, J., Zeckhauser, R. and Hendricks, D. (1994). Investment flows and performance: Evidence from mutual funds, cross-border investments and new issues. Japan, Europe and the international financial markets: Analytical and empirical perspectives, 51-72.

Roston, M. (1996). Mutual Fund Managers and Lifecycle Risk: An Empirical Investigation. Chicago:Univ. Chicago, Dept. Econ.,.

Sargent, T. J. (1993). Bounded rationality in macroeconomics: The arne ryde memorial lectures. OUP Catalogue.

Simon, H. A. (1982). Models of bounded rationality: Empirically grounded economic reason, volume 3. MIT press.

Sirri, E. R. and Tufano, P. (1992). Buying and Selling Mutual Funds: Flows, Performance, Fees, and Services. Division of Research, Graduate School of Business Administration, Harvard University.

Starks, L. T. (1987). Performance incentive fees: An agency theoretic approach. The Journal of Financial and Quantitative Analysis, 22, number 1, 17-32.

Stracca, L. (2006). Delegated portfolio management: A survey of the theoretical literature. Journal of Economic Surveys, 20, number 5, 823-848.

Vissing-Jorgensen, A. (2004). Perspectives on behavioral finance: Does" irrationality" disappear with wealth? evidence from expectations and actions. 139-208.

Zeeman, E.C. (1974). On the unstable behaviour of stock exchanges. Journal of Mathematical Economics, 1, number 1, $39-49$. 


\section{A Notation}

- $M$ - Number of managers

- $N$ - Number of investors

- $\beta$ - Parameter in the density of risky asset's dividend

- $d$ - Dividend paid to investors at the beginning of each period.

- $c$ - Average costs per period incurred by managers, such as the cost of gathering information.

- $y$ - Fraction of asset which is invested into risky asset

- $\delta$ - Random noise, individual investor's error.

- $\epsilon$ - White noise in market price

- $R$ - Return rate

- $\lambda$ - Sensitivity of investor's choice

- $\kappa$ - Inertia parameter

- $n$ - Fraction of investor who follows a type of manager

- $\eta$ - Parameter of adaptive expectation of manager on the change of price

\section{B Market Clearing Price}

The individual demand function for the risky asset is determined by the payoff of investor and his asset in the last period,

$$
D_{i, t}=\frac{A_{i, t-1}^{I} y_{i, t}^{I}}{p_{t}},
$$

where $A_{i, t-1}$ is the asset owned by each investor in the last period $t-1$.

Demand of the market is

$$
\text { Demand }_{t}=\sum D_{i, t} .
$$


Since the supply of risky asset is normalised to 1, market clearing for the risky assets requires

$$
\begin{gathered}
\text { Market Equilibrium : } \text { Demand }_{t}=\text { Supply }_{t}=1, \\
\sum D_{i, t}=1,
\end{gathered}
$$

which gives the market equilibrium pricing equation is

$$
p_{t}=\sum_{i \in n} y_{i, t}^{I} A_{i, t-1}^{I} \text {. }
$$

